\title{
QUALIDADE VOCAL E FORMANTES DAS VOGAIS DE FALAN- TES ADULTOS DA CIDADE DE JOÃO PESSOA
}

\author{
Voice quality and vowel formants of adult subjects \\ from João Pessoa city
}

\author{
Maria Fabiana Bonfim de Lima ${ }^{(1)}$, Zuleica Antonia de Camargo ${ }^{(2)}$, \\ Léslie Piccolotto Ferreira ${ }^{(3)}$, Sandra Madureira ${ }^{(4)}$
}

RESUMO

Objetivo: analisar, do ponto de vista perceptivo-auditivo, a qualidade vocal de um grupo de falantes adultos da cidade de João Pessoa e correlacioná-la às medidas acústicas de freqüência dos formantes (F1, F2 e F3). Métodos: o grupo estudado foi composto por 20 falantes, 10 do gênero masculino e 10 do feminino, na faixa etária compreendida entre 21 e 27 anos, todos nascidos e criados na cidade de João Pessoa. Foram coletadas amostras de fala (três repetições de uma sentença-veículo, dois textos e trechos de fala espontânea), na freqüência de amostragem de $11025 \mathrm{~Hz}$. As gravações foram analisadas do ponto de vista perceptivo-auditivo (ajustes da qualidade vocal) com o uso do roteiro VPAS (Voice Profile Analysis Scheme) e acústico (medidas das freqüências de F1, F2 e F3 da vogal [a] inserida nas amostras). Os dados foram submetidos à análise estatística (análise de componentes principais e composição de clusters para o VPAS e o teste T de Student para as medidas de F1, F2 e F3). Resultados: os ajustes de qualidade vocal predominantes nos falantes do gênero masculino foram: laringe baixa, corpo de língua retraído e voz crepitante. Nos falantes do gênero feminino predominaram ajustes de mandíbula aberta, corpo de língua retraído, corpo de língua abaixado e voz soprosa. As medidas de F1, F2 e F3 mostraram diferenças estatisticamente significantes em ambos os gêneros em relação a falantes de outras regiões do país, com respectivos valores para os falantes masculinos em $p=0,001 ; p=0 ; p=0,003$ e para os falantes femininos em $p=0,002 ; p=0,001 ; p=0$. Conclusão: foram encontradas particularidades na qualidade vocal e na estrutura formântica das vogais dos falantes de João Pessoa e identificadas correlações entre ajustes da qualidade vocal no plano perceptivo-auditivo e aspectos de curto termo no plano acústico.

DESCRITORES: Voz; Avaliação; Percepção da Fala; Acústica da Fala; Percepção Auditiva

(1) Fonoaudióloga, Especialista em Voz, Mestranda em Fonoaudiologia pela Pontifícia Universidade Católica de São Paulo e Pesquisadora do Laboratório de Voz (Labor-vox) da Pontifícia Universidade Católica de São Paulo.

(2) Fonoaudióloga Professora Assistente Doutor do Departamento de Lingüística da Faculdade de Comunicação e Filosofia, Laboratório Integrado de Análise Acústica e Cognição da Pontifícia Universidade Católica de São Paulo, Doutora em Lingüística Aplicada e Estudos da Linguagem pela Pontifícia Universidade Católica de São Paulo.

(3) Fonoaudióloga, Professora Titular do Departamento de Fundamentos da Fonoaudiologia da Faculdade de Fonoaudiologia e do Programa de Estudos Pós-Graduados em Fonoaudiologia da Pontifícia Universidade Católica de São Paulo; Coordenadora e docente do Curso de Especialização em Fonoaoudiologia-Voz da Pontifícia Universidade Católica de São Paulo/ Coordenadoria Geral de Especialização, Aperfeiçoamento e Extensão, Doutora em Distúrbios da Comunicação Humana pela Universidade Federal de São Paulo.

(4) Foneticista Professora Titular do Departamento de Lingüística da Faculdade de Comunicação e Filosofia, Coordenadora do Laboratório Integrado de Análise Acústica e Cognição da Pontifícia Universidade Católica de São Paulo e Professora do Programa de Pós-Graduação em Lingüística Aplicada e Estudos da Linguagem, Doutora em Lingüística Aplicada pela Pontifícia Universidade Católica de São Paulo.

\section{INTRODUÇÃO}

Desde o início da colonização, o português falado no Brasil sofre modificação em relação ao de Portugal, pois em nosso território também aconteceram os fenômenos de contato lingüístico, como deslizamentos lingüísticos, que causaram a incorporação de vários termos e o surgimento de diferentes tipos de sotaques. Tais influências vieram de sociedades indígenas brasileiras, escravos africanos e mesmo de imigrantes europeus como a língua portuguesa ${ }^{1-3}$.

Os falantes expressam-se por meio de diversos tipos de sotaques que variam conforme a região e a condição social. Apesar de ser um aspecto marcante na voz falada e cantada, o sotaque ainda é precariamente explorado em pesquisas do português brasileiro. Até hoje, encontram-se poucas pesquisas a respeito da variedade de sotaques brasileiros no campo fonoaudiológico ${ }^{4,5}$.

"O sotaque é abordado na literatura como conjunto dos hábitos articulatórios (realização de fonemas, entoação) que conferem uma coloração particular, social, dialetal ou estrangeira à fala de um 
indivíduo (sotaque ou pronúncia caipira, nordestina, alemã, entre outras.)" ${ }^{\prime \prime}$ (p. 565).

$\mathrm{Na}$ atuação fonoaudiológica, o sotaque é tratado por meio do conhecimento intuitivo ou da própria vivência profissional. Tais constatações estão presentes tanto no campo de assessoria, com relação ao sotaque de locutores, repórteres, apresentadores e atores, quanto no campo clínico-terapêutico, a fim de se diferenciar aspectos da comunidade lingüística à qual o falante pertence.

Ressalta-se a real necessidade de maior respaldo científico, para que se possa proporcionar aos fonoaudiólogos esclarecimentos sobre as características do modo de falar de cada região, evitando imprecisões na atuação com o universo da fala ${ }^{7}$.

As emissoras de TV e rádio, diretores, professores de teatro e também o setor de telemarketing têm procurado os serviços de fonoaudiólogos com o intuito de amenizar aspectos do sotaque presentes em profissionais que atuam no meio artístico, telejornalístico e em telemarketing, transformando a maneira de falar e a articulação ${ }^{8}$. Tais aspectos são discutidos quanto às implicações éticas ao se abordar o conjunto de modificações de parâmetros sóciolingüísticos, os quais possam descaracterizar o falante diante da sua realidade regional e de sua comunidade lingüística ${ }^{9}$, aspectos esses porém almejados por instituições anteriormente referidas.

Diante de tal discussão, conhecer as particularidades de comunidades de falantes, bem como sua história, sua evolução sócio-cultural, torna-se imperativo no sentido de valorizar o que é peculiar a cada grupo, sem o intuito de impor padrões ou descaracterizar o histórico de falantes ${ }^{7}$.

$\mathrm{Na}$ cadeia sonora da fala, os segmentos consonantais e vocálicos afetam segmentos adjacentes, isto é, sendo a fala um contínuo, observa-se que um segmento pode ser alterado por outro que o precede ou que o sucede. Isto ocorre em razão dos segmentos em questão compartilharem certas propriedades fonéticas ${ }^{10}$ que podem ser evidenciadas tanto na fala de indivíduos sem alteração, como nas alterações, como é o caso das consoantes plosivas produzidas por deficientes auditivos ${ }^{11}$.

O segmento consonantal consiste num som que é produzido com algum tipo de obstrução (parcial ou total) ou subdivisão nas cavidades supraglóticas. Sendo assim, as consoantes do português brasileiro são classificadas pelos seguintes critérios articulatórios: modo de articulação, ponto de articulação e vozeamento ${ }^{10}$.

A vogal é um som gerado por variados graus de aproximação do corpo da língua e do palato, sem que haja fricção da corrente de ar. Assim, os segmentos vocálicos são classificados articulatoriamente levando-se em consideração os seguintes parâmetros: altura da língua; anterioridade/ posterioridade da lín- gua, arredondamento ou não dos lábios ${ }^{10}$, posição de palato mole e mandíbula, os quais determinam as características articulatórias e acústicas da vogal ${ }^{12,13}$.

Do ponto de vista lingüístico, há uma diferença entre vogais e consoantes, com base nas funções destas no sistema lingüístico. Entretanto, acusticamente, esta dicotomia não se sustenta, pois não há uma linha divisória entre vogais e consoantes. Dessa forma, na vogal também estão contidas pistas acústicas da consoante adjacente, pois os formantes das vogais adjacentes são alterados pelo ponto de articulação da consoante que as precedem ${ }^{12}$.

Do ponto de vista acústico, as vogais são consideradas as respostas de ressonância do trato vocal supraglótico e importantes correlatos da posição dos articuladores e da configuração das cavidades ressoadoras ${ }^{14}$. Dessa forma, os sons vocálicos são resultantes da excitação acústica no trato vocal supraglótico, promovi$\mathrm{da}$, inicialmente, pela atividade das pregas vocais ${ }^{15,16}$.

A descrição das vogais remonta a um aspecto fundamental da qualidade vocal, em que se destaca a combinação de ações glótica e supraglótica, tanto do ponto de vista fisiológico, quanto acústico. A inspeção dos formantes das vogais pode dar pistas sobre a posição do trato vocal supraglótico, que, em caráter de longo termo, pode influenciar a qualidade vocal ${ }^{17-20}$. A eleição de aspectos de qualidade vocal e da informação de estrutura formântica revela-se como um primeiro passo na caracterização das particularidades do sinal de fala dos pessoenses: informação da posição do trato vocal supraglótico, tanto nos julgamentos de qualidade vocal, como nos indicativos de medidas dos formantes das vogais.

Com base no modelo fonte-filtro, integrante da descrição da teoria acústica da produção da fala ${ }^{21}$, dependendo da configuração do trato vocal supraglótico, controlada principalmente pela posição da língua, mandíbula e lábios, teremos ênfase em freqüências diferentes, originando diferentes vogais, isto é, diferentes sinais de saída.

As freqüências dos formantes que conferem a identidade fonética às vogais são especialmente as primeiras (F1 e F2). Tais freqüências estão relacionadas respectivamente à conformação da cavidade posterior (faringe), atrás do ponto de máxima constrição lingual (F1) e à cavidade anterior (cavidade oral) à constrição lingual (F2) ${ }^{21}$. Considera-se também que F1 sofra influências da altura de língua e da abertura de boca ${ }^{15,22}$ e F2, variações no eixo ântero-posterior 15,18,21-23. O terceiro formante (F3) está relacionado à passagem da constrição, ou seja, à cavidade atrás da constrição de língua e na frente dela ${ }^{21}$.

O sotaque abrange os aspectos segmentares, tais como a articulação das vogais e das consoantes, e elementos supra-segmentares: entoação, acento, pitch, loudness, taxa de elocução, continuidade, qualidade vocal e ritmo. 
O sotaque nordestino tem como característica principal o fato de as vogais serem todas pronunciadas com a mesma duração e com características próximas ao canto, em comparação com aquelas do Sul do Brasil ${ }^{24}$. Além disso, a entoação segue uma orientação descendente e as vogais são marcadas e abertas.

O termo qualidade vocal refere-se à combinação de ajustes de longo termo de natureza fonatória (laríngeos) e articulatória (supralaríngeos) que são característicos de indivíduos a maior parte do tempo em que falam ${ }^{25}$. Dessa forma, para analisar a qualidade vocal, o autor utilizou uma unidade analítica chamada setting, cuja tradução aproximada seria ajuste. No total, o autor descreveu cinqüenta e três ajustes para a qualidade vocal.

O modelo fonético de avaliação da qualidade vocal, tradução de Vocal Profile Analysis Scheme VPAS ${ }^{26}$, é fundamentado em análises articulatórias, fisiológicas, acústicas e auditivas realizadas pelos fonoaudiólogos e foneticistas com base na habilidade perceptiva dos mesmos em avaliar a qualidade vocal enquanto combinações de ajustes complementares, de natureza fonatória (laríngea) e articulatória (supralaríngea) ${ }^{27}$.

No grupo dos ajustes supralaríngeos, há subcategorias (longitudinais, transversais e velofaríngeos). Nos ajustes supralaríngeos longitudinais há quatro mobilizações: laringe alta, laringe baixa, protrusão labial e labiodentalização. No grupo dos ajustes supralaríngeos transversais são referidas várias mobilizações: labiais (arredondados e estirados), mandibulares (fechada e aberta) e linguais (ponta de língua - avançada e recuada; corpo de língua - avançado, retraído, elevado, abaixado; base de língua constrição e expansão). Finalmente no grupo dos velofaríngeos são descritos os ajustes nasal e denasal. No plano laríngeo, os seguintes ajustes são descritos: modal, falsete, escape de ar, vocal fry (crepitância), voz áspera, voz crepitante e voz soprosa, além dos ajustes de hiperfunção e hipofunção ${ }^{18,27}$.

Diante das possibilidades de combinação originam-se os ajustes compostos, como por exemplo a voz rouca, ajuste composto de escape de ar e do fator aspereza. A caracterização dos ajustes possíveis e previsíveis pelo aparelho fonador baseia-se no conceito de um ajuste de referência: o ajuste neutro. Este consiste numa variedade de ajustes acontecendo simultaneamente em várias áreas do trato vocal, não se caracterizando situação de normalidade ou estado de repouso do aparelho fonador, mas um estado intermediário do aparelho fonador em termos de áreas, o comprimento e atividade de pregas vocais ${ }^{18}$.

Levando-se em conta a variedade de sotaques presentes no Brasil e a necessidade de pesquisas científicas neste tema, um trabalho descreveu, do ponto de vista perceptivo-auditivo e acústico, as ca- racterísticas segmentais (vogais e consoantes) de sotaques das cidades de Recife, Rio de Janeiro e São Paulo ${ }^{4}$.

O tema do sotaque brasileiro na Fonoaudiologia foi abordado, com base na descrição perceptivo-auditiva das características segmentais marcantes do sotaque presente na Cidade das Mangueiras, Belém do Pará ${ }^{\text {, }}$ e posteriormente foram comparados com os das cidades de Recife, Rio de Janeiro e São Paulo ${ }^{4}$.

Dentro dessa multiplicidade, foi eleito, nesta pesquisa, o sotaque paraibano, por ser pouco pesquisado, e especificamente, pelos habitantes da cidade de João Pessoa apresentarem particularidades na qualidade vocal. A caracterização de tais aspectos colabora para o conhecimento mais refinado das variantes de produção sonora no português brasileiro.

Além dos portugueses, a referida cidade sofreu a influência de povos como franceses e holandeses, que ocuparam essa região durante o período colonial. Os povos nativos, os índios (potiguaras), também deram sua contribuição ao sotaque pessoense. Em decorrência disso, os pessoenses caracterizam-se, atualmente, pela riqueza de costumes e crenças, apresentando uma cultura e um modo de falar específico, que traduzem sua origem e suas peculiaridades ${ }^{28}$.

O presente trabalho tem como objetivo analisar, do ponto de vista perceptivo-auditivo, a qualidade vocal de um grupo de falantes adultos nascidos e criados na cidade de João Pessoa e correlacioná-la a informações da esfera acústica, especificamente, às medidas de freqüência dos três primeiros formantes da vogal [a].

\section{MÉTODOS}

Participaram desta pesquisa 20 sujeitos, doravante nomeados de S1 a S20, adultos jovens com nível sócio-econômico semelhante, selecionados com base na formação superior (tanto completa como em curso). Dez eram do gênero masculino e dez do feminino, na faixa etária compreendida entre 21 e 27 anos, com média de idade de 23,35 anos evitando-se assim os extremos em faixas etárias relativas à puberdade e à senescência, todos nascidos e criados na cidade de João Pessoa, capital da Paraíba. Além disso, os pais dos falantes da pesquisa eram em sua maioria naturais da região do próprio estado da Paraíba (Figura 1).

Para evitar que os participantes da pesquisa apresentassem pronúncias trabalhadas, foram escolhidas pessoas que não atuassem em meios de telecomunicação e artístico ou tivessem formação em locução. Foram ainda excluídos do grupo indivíduos que apresentassem distúrbio de articulação dos sons, distúrbio auditivo, bilingüismo, bem como alteração de qualidade vocal de origem glótica. Tais dados foram coletados por meio de questionário aplicado na 
sessão de coleta de amostra de fala, constando dos itens: gênero, faixa etária, escolaridade, profissão, referência a queixas de fala, voz e audição e domínio de língua estrangeira. No caso da qualidade vocal, os critérios de exclusão basearam-se em referência dos examinadores e manifestação de alteração glótica em grau 4 a 6 no roteiro adotado para avaliação perceptivo-auditiva.

O corpus constou de leituras de uma sentençaveículo, dois textos e trechos de fala espontânea. Os falantes fizeram três repetições da sentença e dos textos em ordem aleatória. Como sentença-veículo utilizou-se: "Diga pata baixinho", da qual foi selecionado a vogal [a] da sílaba tônica do vocábulo "pata" para a extração das medidas dos formantes. Os dois textos (padronizados) utilizados na coleta das amostras foram:

1. Texto padronizado utilizado no Laboratório Integrado de Análise Acústica e Cognição ${ }^{18}$.

"Há um tempo atrás, li uma lenda sobre uma jornada de um grupo de pássaros à procura do rei ideal. Para líder do grupo, os pássaros escolheram a águia que era admirada pelas aves por ter vencido o medo de voar a lugares desconhecidos. No dia marcado para o início da viagem, ela reuniu o grupo e procurou motivá-lo a percorrer o caminho. O papagaio, adornado com seu colar de fogo, foi o primeiro a declarar que estava pronto para partir. A arara parecia estar animada e convocou a todos para iniciar a marchar. Sua alegria contagiou o tímido pato, a bela patativa, o valente falcão, a educada codorna, o sabiá branco, o querido uirapuru, a aplicada coruja, o dedicado canário, o orgulhoso pavão, a elegante garça, o esperto bicudo, a meiga rolinha, o dedicado pardal e o animado pombo. Aáguia sabia que o trajeto era difícil, e que o rei só seria encontrado por aquele que tomasse o rumo correto. A sábia águia já havia percorrido o caminho e descobrira que só aquele que segue em direção aos vales do amor e da humildade encontra a realeza dentro de si. Um pássaro em viagem representa o homem com suas fraquezas, ideais e qualidades em busca do criador" (texto de composição mista entre sons surdos e sonoros).

2. Letra de música de autoria de Luiz Gonzaga, A vida do viajante: "Minha vida é andar por esse país/ Pra ver se um dia descanso feliz/Guardando as recordações/Das terras onde passei/Andando pelos sertões/E dos amigos que lá deixei/Chuva e sol/ Poeira e carvão/Longe de casa sigo o roteiro/Mais uma estação/E alegria no coração/Mar e terra/ Inverno e verão/Mostro o sorriso/ Mostro a alegria/Mas eu mesmo não/E a saudade no coração".

Os trechos de fala espontânea foram compostos pelas respostas a perguntas realizadas aos participantes da pesquisa no momento da coleta de dados (Como você chegou aqui? O que você gosta de fazer em João Pessoa? O que você fez no final de sema- na? O que você acha que mais marca os pessoenses?).

O material de leitura foi digitado em fonte Arial, tamanho 14, sendo as frases apresentadas individualmente, em forma de fichas.

A gravação foi realizada em estúdio profissional particular da cidade de João Pessoa. Os falantes foram individualmente acomodados em cabina acusticamente tratada, com uso de microfone profissional unidirecional da marca Eletrovoice, com distância de $15 \mathrm{~cm}$ da boca, acoplado a um computador Athlon 64, com placa de som Audigy da Creative e mesa de som Roland, modelo VS2480, com HD e 24 canais de gravação.

As amostras de fala foram exploradas do ponto de vista perceptivo-auditivo e acústico, para as quais foram adotados procedimentos de digitalização distintos: formatos áudio e dados respectivamente.

As amostras digitalizadas no formato áudio foram analisadas do ponto de vista perceptivo-auditivo. Trechos de fala correspondentes às respostas para as perguntas, bem como trechos de textos foram apresentados a três juízes experientes no julgamento de qualidade vocal com base fonética, dois fonoaudiólogos e um foneticista. Estes, com o uso do roteiro VPAS, analisaram individualmente o material e registraram os achados em protocolo específi$\mathrm{CO}^{27}$. Ao final, tendo em mãos as respostas, chegouse ao consenso das avaliações.

As mesmas amostras foram digitalizadas em formato dados (extensão .wav), $11025 \mathrm{~Hz}$ de freqüência de amostragem, 16 bits e foram submetidas à análise acústica com a utilização do software Praat (4.3.22), disponível no site www.fon.hum.uva.nl/praat/ , para extração das medidas da freqüência dos formantes (F1, F2 e F3) da vogal [a], em sílaba tônica. As vogais selecionadas para análise foram sublinhadas e negritadas nos textos anteriormente apresentados.

A extração das medidas de freqüência de formantes envolveu o procedimento de espectrografia de banda larga, seguido da localização dos trechos com melhor definição do traçado dos formantes, no período estacionário da vogal. No referido ponto, foi possível traçar o espectro LPC (Linear Predictive Code), do qual foram extraídas as medidas da frequência $(\mathrm{em} \mathrm{Hz})$, dos três primeiros picos espectrais (F1, F2 e F3).

O projeto de pesquisa foi aprovado pelo Comitê de Ética do Programa de Pós Graduação em Fonoaudiologia da Pontifícia Universidade de São Paulo sob o número 0040/ 2005.

Os resultados da avaliação perceptivo-auditiva foram submetidos a tratamento estatístico pelo método de análise de componentes principais e composição de clusters (análise fatorial). As medidas de freqüência dos formantes foram submetidas à análise 
estatística pelo teste T de Student, com nível de significância de 5\%, tendo como referência de medida dos três formantes da vogal [a], para falantes do gênero masculino: F1[a]: 807 Hz; F2[a]: 1440Hz e F3[a]: $2524 \mathrm{~Hz}^{29}$. Para os falantes do gênero feminino os valores referenciais dos formantes da vogal [a] foram considerados em vários contextos: $F 1$ [pa]: 843 Hz, F2[pa]: 1387 Hz, F3[pa]: 2279 Hz, F1[ta]: 792 Hz, F2[ta]: $1382 \mathrm{~Hz}, \mathrm{~F} 3[\mathrm{ta}]: 2866 \mathrm{~Hz}, \mathrm{~F} 1[\mathrm{ka}]: 797$ Hz, F2[ka]: 1499 Hz e F3[ka]: $2135 \mathrm{~Hz}^{12}$. Vale ressaltar que para os falantes do gênero feminino, como não foi encontrada referência para vogal [a] com a consoante [8], os valores foram comparados com a consoante [t], uma vez que apresentam pontos articulatórios próximos.

\section{RESULTADOS}

Os resultados da avaliação peceptivo-auditiva de qualidade vocal são apresentados separadamente para falantes dos gêneros masculino (Figura 2) e feminino (Figura 3).

Nos falantes do gênero masculino predominaram ajuste laringe baixa, corpo de língua retraído e voz crepitante (Figura 2). Para os falantes do gênero feminino houve um predomínio dos ajustes de mandíbula aberta, corpo de língua retraído, corpo de língua abaixado e voz soprosa (Figura 3).

A análise de componentes principais e composição de clusters revelou o agrupamento de 20 falantes em 3 categorias. No grupo 1 (S01, S02, S03, S04, S05, S06, S07, S09, S10, S19 e S20) houve a ocorrência dos ajustes supralaríngeos (laringe baixa, lábios protuídos, dorso de língua abaixado e nasalidade) e ajuste laríngeo como o de voz crepitante. Destaca-se nesta categoria a predominância de falantes do gênero masculino.

A composição do grupo 2 (S15 e S18) revelou forte influência da ausência de abertura de mandíbula e de dorso de língua retraído para ambos os falantes e presença de lábios estirados em um dos falantes (S15). Neste grupo, todos os falantes eram do gênero feminino.

O grupo 3 (S08, S11, S12, S13, S14 e S16) caracterizou-se pela presença de ajustes supralaríngeos (dorso de língua elevado e laringe alta) e ajustes laríngeos, em sua maior concentração, totalizando seis falantes distribuídos em : voz soprosa (4), voz áspera (1) e hiperfunção (1).

Do ponto de vista acústico, os resultados das medidas de freqüência dos três primeiros formantes (F1, F2, F3) são apresentados separadamente para falantes do gênero masculino (Tabela 1) e feminino (Tabela 2).

Com exceção das medidas de F1 para uma repetição de pata, F2 para duas emissões de arara e F3 para as emissões de pata e de uma repetição de casa, todos os valores de freqüência de formantes para o gênero masculino estiveram diminuídos em relação à referência, com significância estatística.

Com exceção das medidas de F2 para uma repetição de casa e F3 para duas emissões do vocábulo arara, todos os valores de freqüência de formantes para o gênero feminino estiveram aumentados, com significância estatística.

\begin{tabular}{|cc|c|l|l|}
\hline IDENTIFICAÇÃo & GÊNERO & IDADE & FORMAÇÃo & $\begin{array}{l}\text { NATURALIDADE } \\
\text { DOS PAIS }\end{array}$ \\
\hline S1 & masculino & 23 & Superior em curso & $\begin{array}{l}\text { Ambos de outras cidades } \\
\text { nordestinas }\end{array}$ \\
\hline S2 & masculino & 21 & Superior em curso & Ambos pessoenses \\
\hline S3 & masculino & 24 & Superior em curso & $\begin{array}{l}\text { Ambos de outras cidades } \\
\text { nordestinas }\end{array}$ \\
\hline S4 & masculino & 22 & Superior em curso & $\begin{array}{l}\text { Um pessoense e o outro de } \\
\text { uma cidade da PB }\end{array}$ \\
\hline S5 & masculino & 21 & Superior em curso & Ambos pessoenses \\
\hline S6 & masculino & 27 & Superior completo & Ambos pessoenses \\
\hline S7 & masculino & 25 & Superior completo & Ambos pessoenses \\
\hline S8 & masculino & 27 & Superior completo & $\begin{array}{l}\text { Um pessoense e o outro de } \\
\text { uma cidade da PB }\end{array}$ \\
\hline S9 & masculino & 21 & Superior em curso & $\begin{array}{l}\text { Ambos de outras cidades } \\
\text { nordestinas }\end{array}$ \\
\hline S10 & masculino & 23 & Superior em curso & $\begin{array}{l}\text { Ambos de outras cidades } \\
\text { nordestinas }\end{array}$ \\
\hline S11 & feminino & 24 & Superior em curso & $\begin{array}{l}\text { Ambos de outras cidades } \\
\text { nordestinas }\end{array}$ \\
\hline S12 & feminino & 22 & Superior em curso & $\begin{array}{l}\text { Ambos de outras cidades } \\
\text { nordestinas }\end{array}$ \\
\hline S13 & feminino & 25 & Superior completo & $\begin{array}{l}\text { Ambos de outras cidades } \\
\text { nordestinas }\end{array}$ \\
\hline S14 & feminino & 24 & Superior completo & $\begin{array}{l}\text { Um do norte e o outro de uma } \\
\text { cidade da PB }\end{array}$ \\
\hline
\end{tabular}


Lima MFB, Camargo ZA, Ferreira LP, Madureira S

\begin{tabular}{|ll|c|l|l|}
\hline S15 & feminino & 24 & Superior completo & $\begin{array}{l}\text { Ambos de outras cidades } \\
\text { nordestinas }\end{array}$ \\
\hline S16 & feminino & 23 & Superior completo & $\begin{array}{l}\text { Um pessoense e o outro de } \\
\text { uma cidade da PB }\end{array}$ \\
\hline S17 & feminino & 23 & Superior em curso & $\begin{array}{l}\text { Ambos de outras cidades } \\
\text { nordestinas }\end{array}$ \\
\hline S18 & feminino & 23 & Superior em curso & $\begin{array}{l}\text { Ambos de outras cidades } \\
\text { nordestinas }\end{array}$ \\
\hline S19 & feminino & 23 & Superior incompleto & $\begin{array}{l}\text { Ambos de outras cidades } \\
\text { nordestinas }\end{array}$ \\
\hline S20 & feminino & 22 & Superior completo & $\begin{array}{l}\text { Ambos de outras cidades } \\
\text { nordestinas }\end{array}$ \\
\hline
\end{tabular}

Figura 1- Dados referentes ao gênero, idade, formação e naturalidade dos pais do grupo estudado

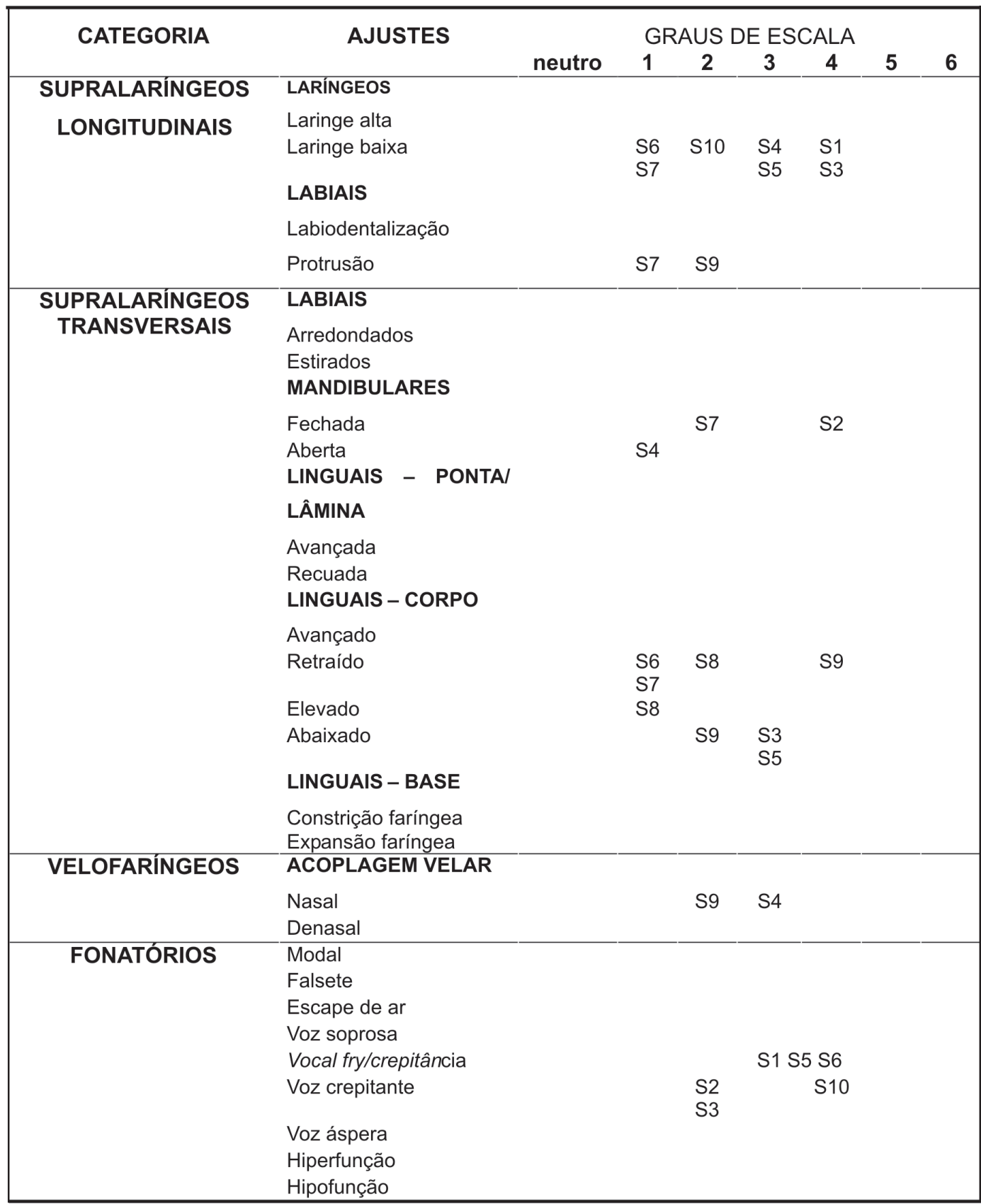

Figura 2 - Julgamento perceptivo-auditivo da qualidade vocal dos falantes nativos da cidade de João Pessoa do gênero masculino (S1 a S10)

Rev CEFAC, São Paulo, v.9, n.1, 99-109, jan-mar, 2007 


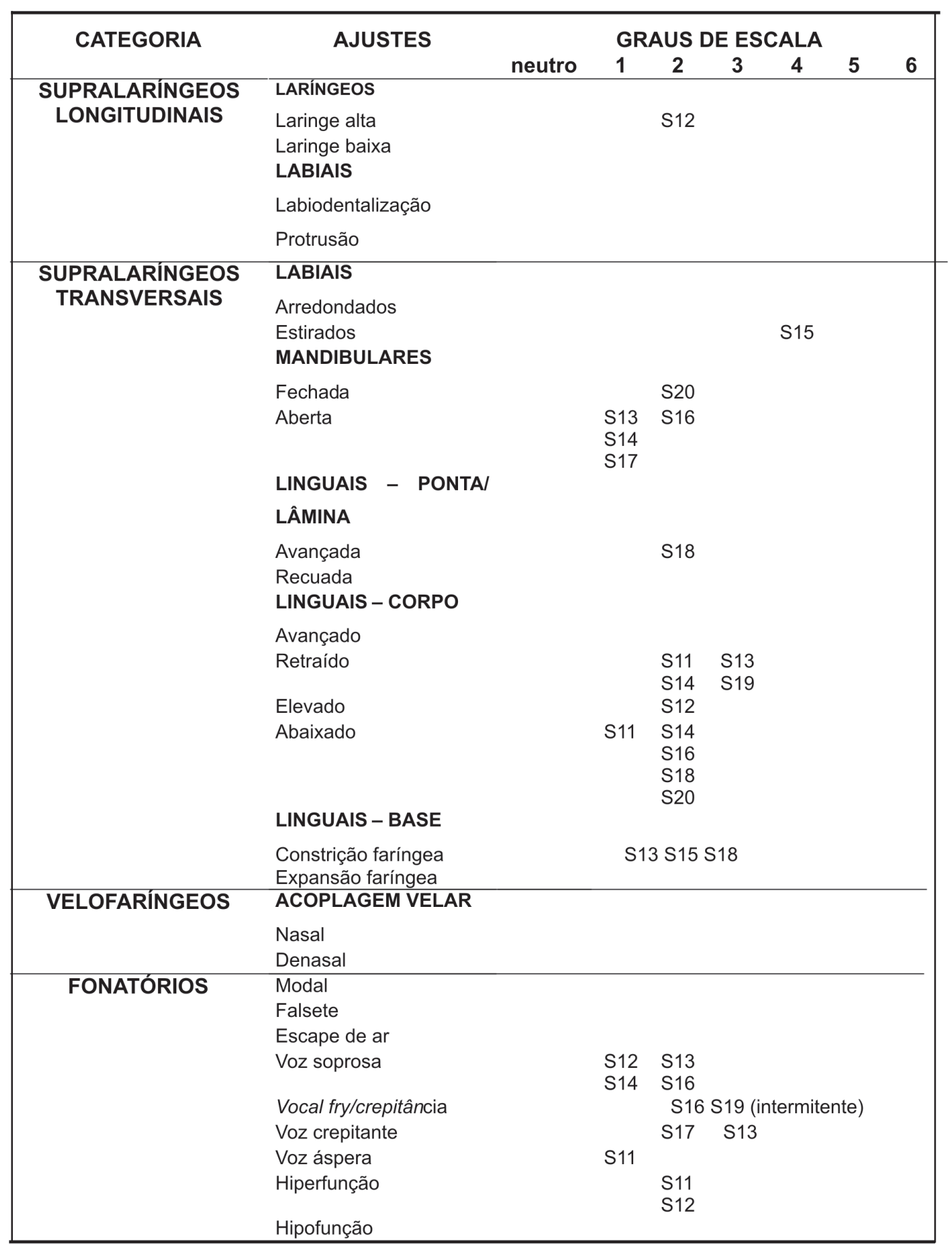

Figura 3 - Julgamento perceptivo-auditivo da qualidade vocal dos falantes nativos da cidade de João Pessoa do gênero feminino (S11 a S20) 
Tabela 1 - Valores da média da freqüência dos formantes (F1, F2, F3) em Hertz (Hz), desvio padrão (DP) e valores de $\mathrm{p}$ para a emissão da vogal [a] nos contextos dos vocábulos pata, arara e casa dos falantes do gênero masculino

\begin{tabular}{lcccccccccc}
\hline & \multicolumn{3}{c}{$F 1$} & \multicolumn{3}{c}{$F 2$} & \multicolumn{3}{c}{$F 3$} \\
\hline Estímulo & média(Hz) & DP & $p$ & média(Hz) & DP & $p$ & média(Hz) & DP & p-valor \\
pata1 & 700 & 74 & $0,001^{*}$ & 1307 & 72 & $0^{*}$ & 2571 & 115 & $0,228^{*}$ \\
pata2 & 754 & 104 & 0,145 & 1312 & 123 & $0,010^{*}$ & 2530 & 130 & $0,880^{*}$ \\
pata3 & 732 & 84 & $0,021^{*}$ & 1262 & 81 & $0^{*}$ & 2502 & 177 & $0,710^{*}$ \\
arara1 & 695 & 82 & $0,002^{*}$ & 1376 & 87 & $0,046^{*}$ & 2396 & 161 & $0,034^{*}$ \\
arara2 & 685 & 86 & $0,002^{*}$ & 1396 & 102 & 0,209 & 2382 & 189 & $0,042^{*}$ \\
arara3 & 697 & 91 & $0,004^{*}$ & 1411 & 103 & 0,401 & 2398 & 133 & $0,016^{*}$ \\
casa1 & 671 & 57 & $0^{*}$ & 1344 & 109 & $0,022^{*}$ & 2340 & 190 & $0,014^{*}$ \\
casa2 & 643 & 63 & $0^{*}$ & 1349 & 103 & $0,022^{*}$ & 2318 & 164 & $0,003^{*}$ \\
casa3 & 676 & 56 & $0^{*}$ & 1341 & 120 & $0,029^{*}$ & 2420 & 265 & 0,247 \\
\hline
\end{tabular}

Teste T de Student *estatisticamente significante

Tabela 2 - Valores da média da freqüência dos formantes (F1, F2, F3) em Hertz (Hz), desvio padrão (DP) e valores de $\mathrm{p}$ para a emissão da vogal [a] nos contextos dos vocábulos pata, arara e casa dos falantes do gênero feminino

\begin{tabular}{|c|c|c|c|c|c|c|c|c|c|}
\hline & & $F 1$ & & & $F 2$ & & & F3 & \\
\hline estímulo & média(Hz) & $\mathrm{DP}$ & $P$ & média(Hz) & DP & $\mathrm{p}$ & média(Hz) & $\mathrm{DP}$ & p valor \\
\hline pata1 & 1001 & 118 & $0,002^{*}$ & 1630 & 163 & $0,001^{*}$ & 2831 & 309 & $0^{*}$ \\
\hline pata2 & 973 & 124 & $0,009^{*}$ & 1556 & 139 & $0,004^{*}$ & 2839 & 300 & $0^{*}$ \\
\hline pata3 & 979 & 80 & $0^{*}$ & 1581 & 102 & $0^{*}$ & 2824 & 333 & $0,001^{*}$ \\
\hline arara1 & 963 & 100 & $0^{*}$ & 1641 & 152 & $0^{*}$ & 2644 & 309 & $0,050^{*}$ \\
\hline arara2 & 954 & 110 & $0,001^{*}$ & 1606 & 161 & $0,002^{*}$ & 2726 & 294 & 0,167 \\
\hline arara3 & 976 & 82 & $0^{*}$ & 1625 & 154 & $0,001^{*}$ & 2741 & 253 & 0,154 \\
\hline cassa1 & 951 & 127 & $0,004^{*}$ & 1648 & 133 & $0,006^{*}$ & 2749 & 270 & $0^{*}$ \\
\hline cassa2 & 948 & 125 & $0,004^{*}$ & 1599 & 142 & 0,052 & 2676 & 252 & $0^{*}$ \\
\hline casa3 & 933 & 138 & $0,012^{*}$ & 1630 & 160 & $0,029^{*}$ & 2707 & 302 & $0^{*}$ \\
\hline
\end{tabular}

Teste T de Student *estatisticamente significante 


\section{DISCUSSÃO}

Os ajustes de qualidade vocal que predominaram nos falantes do gênero masculino foram: laringe baixa, corpo de língua retraído e voz crepitante, e para os falantes do gênero feminino, mandíbula aberta, corpo de língua retraído, corpo de língua abaixado e voz soprosa.

A maior parte das medidas de formantes dos falantes do gênero feminino ficou acima dos valores de referência ${ }^{12}$. Por outro lado, a grande parcela dos valores dos formantes do gênero masculino ficou abaixo da referência adotada ${ }^{29}$.

$\mathrm{O}$ ajuste de laringe baixa promove o aumento da extensão total do trato vocal, tendo como conseqüência acústica a diminuição da freqüência de todos os formantes, especialmente, dos mais baixos e a tendência à diminuição dos valores de f0, o que correspondeu aos achados do grupo de falantes do gênero masculino ${ }^{18,26}$ (Figura 2 e Tabela 1).

Os efeitos acústicos dos ajustes de mandíbula aberta e fechada (movimentos verticais, horizontais, laterais e rotação) apresentam similaridade com aqueles referentes aos ajustes de lábios (transversais) e aos demais longitudinais, incluindo elevação da freqüência de $\mathrm{F} 1$ proporcional ao aumento da abertura de mandíbula ${ }^{18}$. Tais achados foram compatíveis com ajustes de mandíbula aberta por falantes do gênero feminino (S13, S14, S16 e S17) e do gênero masculino (S4) e com ajustes de mandíbula fechada também em ambos os gêneros, feminino (S20) e masculino (S2, S7) (Figura 3 e Tabela 2).

Os ajustes de ponta, lâmina e corpo de língua apresentam um componente de anteriorização e um de posteriorização, no que se refere ao ponto de articulação dos sons consonantais. Dessa forma, acusticamente, o componente de posteriorização apresenta uma tendência geral a aumento da freqüência de F1 e diminuição de F2, correspondendo aos pontos articulatórios: velarizado, uvularizado, faringealizado e faringolarigealizado ${ }^{25}$. O ajuste de corpo de língua retraído foi identificado em quatro falantes do gênero masculino (S6, S7, S8 e S9) e quatro do gênero feminino (S11, S13, S14, S19). A ocorrência de tal ajuste pode ser conseqüência da glotalização presente nos sons correspondentes ao fonema / $r$ / na posição de coda da sílaba, em que ocorre a neutralização (arquifonema/R/). Tal aspecto de posteriorização de articulação favoreceria a mobilização do dorso de língua em direção posterior. Esta hipótese acentua a importância da abordagem integrada entre os planos segmental e supra-segmental no estudo do sotaque e dos efeitos de coarticulação, inclusive na qualidade vocal.

Em contrapartida, também foram encontrados ajuste de corpo de língua abaixado em cinco falantes do gênero feminino (S11, S14, S16, S18 e S20) e em três falantes do gênero masculino (S3, S5 e S9).

$\mathrm{O}$ ajuste de constrição faríngea promove o fechamento da parte média a orofaringe por contração das paredes de faringe e/ou retração do dorso de língua, proporcionando aumento de $\mathrm{F} 1$ e rebaixamento de $\mathrm{F} 2{ }^{26}$. Tal ajuste foi identificado no grupo do gênero feminino (S13, S15 e S18) e pode ser confundido com nasalidade ${ }^{30}$.

A voz crepitante (combinação dos ajustes vocal fry e modal) apresenta pulsos irregulares e baixos valores de f0. Na designação original, seria a referida como creaky voice. No ajuste de vocal fry (crepitância), as pregas vocais encontram-se aduzidas (volumosas e comprimidas), com tensão adutora alta e longitudinal baixa. $O$ resultado auditivo é de um trem de pulsos e os valores de f0 são baixos. Na literatura fonética é também referido como laringealização ${ }^{18}$. Este tipo de voz foi encontrado no grupo dos falantes do gênero masculino (S1, S5 e S6) e do gênero feminino (S13, S16, S17 e S19).

O ajuste de voz soprosa (combinação do componente soprosidade e do ajuste modal) associado à hipofunção corresponde à redução da tensão da musculatura do sistema muscular fonatório, levando ao escape de ar maior do que no ajuste de voz soprosa com hiperfunção, porém com menos fricção. $\mathrm{O}$ componente de soprosidade promove variação do ajuste modal, resultando em modo de vibração insuficiente e acompanhado por leve e discreta fricção audível. A compressão medial é mínima e o esforço muscular é pequeno. Por esta razão, vai combinar com o ajuste modal e tem pouco efeito auditivo ${ }^{26,18}$. Tal qualidade vocal foi encontrada apenas no gênero feminino (S12, S13, S14 e S16), e isso pode ser em razão da presença de fenda triangular posterior comum em muIheres adultas ${ }^{31}$.

Os valores aumentados na maior parte das emissões para as freqüências de F1, F2 e F3 em falantes do gênero feminino sugerem a influência de ajustes como laringe alta, e, especialmente, corpo de língua abaixado, ponta de língua avançada e constrição faríngea (Tabela 2).

Os dados da análise de componentes principais e composição de clusters novamente apontam ajustes importantes na delimitação de grupos. Nos grupos 2 e 3 observou-se concentração de falantes do gênero feminino, sendo que o grupo 2 apresentou predomínio de ajustes de constrição faríngea e ausência de ajustes laríngeos, contrapondo-se ao grupo 3, no qual houve presença de ajustes laríngeos, juntamente com ajustes supralaríngeos de língua.

Os achados apresentados revelam particularidades de qualidade vocal, com correspondências entre os planos de percepção auditiva e da acústica em falantes nascidos e criados na cidade de João Pessoa, inclusive com diferenciação entre gêneros, assim como, estudos anteriores expuseram particula- 
ridades de outras comunidades lingüísticas no português brasileiro ${ }^{4,5}$. Tais achados reforçam a necessidade de maior conhecimento dos perfis de produção de fala de diferentes comunidades lingüísticas, como forma de aprofundar a incursão do fonoaudiólogo na situação de reabilitação e de assessoria.

Os achados indicam um vasto trabalho a ser realizado para que se tenha uma clara visão da realidade lingüística brasileira, e de como atuar com tal variedade de sotaques. A presente pesquisa avança ao valorizar a incorporação do VPAS com a finalidade de descrever as características mais marcantes na qualidade vocal de falantes adultos nascidos e criados na cidade de João Pessoa, capital da Paraíba e correlacioná-las aos parâmetros de configuração das cavidades supraglóticas, por meio de medidas acústicas de freqüência de formantes.

\section{CONCLUSÃO}

Foram encontradas particularidades na qualidade vocal dos falantes de João Pessoa do ponto de vista perceptivo-auditivo (ajustes laríngeos e supralaríngeos) e acústico (formantes -F1, F2 e F3- da vogal [a]).

No plano dos ajustes de qualidade vocal predominaram laringe baixa, corpo de língua retraído e voz crepitante para falantes do gênero masculino; e mandíbula aberta, corpo de língua retraído, corpo de língua abaixado e voz soprosa para falantes do gênero feminino. As medidas de F1, F2, F3 revelaram diferenças significantes em relação às referências, com tendência à diminuição no gênero masculino e ao aumento no gênero feminino.

\begin{abstract}
Purpose: to analyze, from the auditory perception point of view, the voice quality of a group of adult speakers from the city of João Pessoa and correlate it to the acoustic measures of the formant frequencies (F1, F2 and F3). Methods: the studied group was comprised by 20 speakers, 10 men and 10 women, in the age group between 21 and 27 years, all born and raised in the city of João Pessoa. Speech samples were collected (three repetitions of a sentence-vehicle, two texts and passages of spontaneous speech), in the sampling frequency: $11025 \mathrm{~Hz}$. The recordings were analyzed from the auditory perception (voice quality settings) with the use of the VPAS (Voice Profile Analysis Scheme) and acoustic point of view (measures of F1, F2 and F3 frequencies of the vowel [a] inserted in the samples). Data were submitted to statistical analysis (analysis of main components and composition of clusters for VPAS and T test of Student for measures of F1, F2 and F3 frequencies). Results: the predominant voice quality settings in the male speakers were low larynx, retracted tongue body and creaky voice. In the female speakers, the settings of open jaw prevailed, retracted tongue body, lowered tongue body and whispery voice. F1, F2 and F3 frequencies measures showed statistically significant differences in both genders in relation to speakers of other areas of the country, with respective values for the masculine speakers in $p=0.001 ; p=0 ; p=0.003$ and for the female speakers in $p=0.002 ; p$ $=0.001 ; p=0$. Conclusion: particularities were found in the voice quality and in the formant structure of the speakers' vowels from João Pessoa and correlations identified among settings of the voice quality in the auditory perception plan and short-term aspects in the acoustic plan.
\end{abstract}

KEYWORDS: Voice; Evaluation; Speech Perception; Speech Acoustics; Auditory Perception

\section{REFERÊNCIAS}

1. Moreira MLB. O português do Brasil: uma retrospectiva histórica-linguística de 1500 a 1800. Hispania. 1996; 79(3):419-28.

2. Orlandi EP. A língua brasileira. [periódico online] Rev Cienc Cult. 2005. Disponível em: URL: http:// cienciaecultura.bvs.br/scielo.php?pid=S000967252005000200016\&script=sci_arttext\&tlng=pt 3. Pagotto EG. Variedades do português no mundo e no Brasil. [periódico online] Rev Cienc Cult 2005. Disponível em: URL: http://cienciaecultura.bvs.br/ s c i e I o.ph p ? p i d =S 00009 -
$67252005000200017 \&$ script=sci $\quad$ arttext\&tlng=pt 4. Lira ZS. Descrição fonética das características segmentais dos sotaques de Recife, Rio de Janeiro e São Paulo: análise perceptivo-auditiva e acústica [mestrado]. São Paulo (SP): Pontifícia Universidade Católica; 2001.

5. Chaves AF. Análise perceptivo-auditiva das características segmentais do sotaque de falantes da cidade de Belém do Pará. [monografia]. São Paulo (SP): Pontifícia Universidade Católica; 2002.

6. Dubois J, Giacomo L, Marcellesi C, Marcellesi JB, Mevel JP. Dicionário de lingüística. São Paulo: Cultrix; 1998. 
7. Bagno M. Preconceito lingüístico: o que é, como se faz. 2. ed. São Paulo: Loyola; 1999.

8. Oliveira MC. As marcas de regionalidade em atores de teatro. Rev Soc Bras Fonoaudiol. 2001; 6(2):47-53. 9. Lopez DC, Dittrich IJ. Identidade lingüística: regionalização ou padronização? [periódico online] Ciênc Comun. 2005. Disponível em: URL: http:// www.bocc.ubi.pt/pag/lopez-debora-dittrich-ivo-identidade-linguistica.pdf

10. Silva TC. Fonética e fonologia do português: roteiro de estudos e guia de exercícios .7. ed. São Paulo: Contexto; 2003.

11. Barzaghi L, Madureira S. Percepção de fala e deficiência de audição: elaboração de um procedimento de avaliação da percepção auditiva das plosivas do português brasileiro. Rev Dist Comun. 2005; 17(1):87-99.

12. Mendes BCA. Estudo fonético-acústico das vogais do português brasileiro: dados da produção e percepção da fala de um sujeito deficiente auditivo [doutorado]. São Paulo (SP): Pontifícia Universidade Católica; 2003.

13. França A. Problems in the tense variant of carioca speech. Delta 2004; 20:33-58.

14. Martins RD. Ouvir falar: introdução à fonética do português. 3. ed. Lisboa: Caminho; 1988.

15. Stevens KN, House AS. An acoustical theory of vowel production and some of its implications. J Speech Hear Res. 1961; 4:303-20.

16. Camargo Z. Da fonação à articulação: princípios fisiológicos e acústicos. Fonoaudiol Bras. 1999; 2(2):14-9.

17. Pinho SMR, Pontes PAL, Abílio SO, Ganança MM. Configurações do trato vocal nas vogais orais do português. Acta AWHO. 1988; 12:124-36.

18. Camargo Z, Madureira S, Tsuji DH. Analysis of dysphonic voices based on the interpretation of acoustic, physiological and perceptual data. In: 16th International Seminar on Speech Production
Proceedings. Sidney; 2003.

19. Jorge M, Gregio FN, Camargo Z. Qualidade vocal de indivíduos submetidos a laringectomia total: aspectos acústicos de curto e de longo termo em modalidades de fonação esofágica e traqueoesofágica. Rev CEFAC. 2004; 6(3):319-28.

20. Cukier S, Camargo Z. Abordagem da qualidade vocal em um falante com deficiência auditiva: aspectos acústicos relevantes do sinal de fala. Rev CEFAC. 2005; 7(1):93-101.

21. Fant G. Speech sounds and features. Cambridge: MIT Press; 1973.

22. Lindblom BE, Sundberg JE. Acoustical consequences of lip, tongue, jaw, and larynx movement. J Acoust Soc Am. 1971; 50(4):1166-79.

23. Kent RD. Vocal tract acoustics. J Voice 1993; 7(2):97-117.

24. Marroquim M. A língua do nordeste: Pernambuco e Alagoas. 3. ed. Curitiba: HD Livros; 1996.

25. Laver J. Principles of phonetics. New York: Cambridge University Press; 1994.

26. Laver J. Phonetic evaluation of voice quality. In: Kent RD, Ball MJ. Voice quality measurement. San Diego: Singular Publishing Group; 2000. p. 37-48.

27. Camargo Z, Vilarim GS, Cukier S. Parâmetros perceptivo-auditivos e acústicos de longo termo da qualidade vocal de indivíduos disfônicos. Rev CEFAC. 2004; 6(2): 189-96.

28. Mello JOA. História da Paraíba: lutas e resistência. 9. ed. João Pessoa: A União; 2002.

29. Behlau MS, Pontes PA, Tosi O, Ganança MM. Análise espectográfica de formantes das vogais do poruguês brasileiro falado em São Paulo. Acta AWHO. 1988; 7:67-73.

30. Hanayama EM, Tsuji DH, Pinho SMR. Voz metálica: estudo das características fisiológicas. Rev CEFAC. 2004; 6(4):436-45.

31. Behlau M. Voz: o livro do especialista. Rio de Janeiro: Revinter; 2001.
RECEBIDO EM: 30/08/06

ACEITO EM: 18/11/06

Endereço para correspondência:

R. Homem de Mello, 717 / 1.123

São Paulo - SP

CEP: 05007-002

E-mail: fbl_fono@yahoo.com.br 